did) were observed, or which manifested precocious sexual instincts which would be gratified by any means whatever, and in a few cases there were observed abnormal cravings for food (gluttony), as well as for drink which never seemed to be satisfied. Finally, the morphia habit was observed in a good many instances.

Mental Disorders simulating Neurasthenia.-Professor E. Kraepelin, of Heidelberg, ${ }^{15}$ states that owing to the current lack of precision in the use of medico psychological language the term neurasthenia has been frequently applied to the most varied forms of nervous disorders, and has often been misused as a designation for the initial stages of serious mental disorders before the precise nature of the latter could be apprehended. The differential diagnosis of neurasthenia from mental and cerebral diseases which may simulate it is therefore important. This applies especially to the early stages of general paralysis of the insane. The characteristic paretic speech (tremulous, embarrassed, and with slurring difficult sounds) and the oculo-papillary symptoms will, if present, serve to indicate general paralysis. The first indication of general paralysis may, however, be a maniacal outbreak which will serve to distinguish it positively from neurasthenia when diagnosis has been difficult. Some forms of dementiapraecox or mental enfeeblement supervening in adolescence are also liable to be confounded with neurasthenia, and this is especially so with the hebephrenic form of dementia præcox. The presence of masturbation, with its debilitating effects upon the central nervous system, may make the resemblance to neurasthenia more marked in the early stages of the psychoses of adolescence. "It is important to discriminate between neurasthenia and these psychoses of adolescence because useless and expensive efforts to obtain a cure, e.g., by hydrotherapy, electricity, and hypnosis, may be avoided if it were known that the disease was dementia præcox and not neurasthenia, as only the latter could react favourably to such therapeutic measures. The development of such symptoms as stupidity and mental automatism, muscular hypertonicity and catalepsy, mannerisms, stereotyped attitudes and gestures, and negativism or resistance to every movement required -any one or two of these signs should lead us to suspect the presence of dementia præcox. Finally, there is a group of mental affections, such as maniacal-depressive insanity and circular insanity, which in the prodromal stages exhibit the appearance of neurasthenia. On inquiring into the psychical condition of these patients, however, there will be detected various symptomatic elements which, though present in neurasthenia, are found to be developed to a more intense degree in these mental cases, viz., great prostration with incapacity for work, a gloomy and clouded disposition, hypochondriacal apprehensions and fears, headache and cephalic paraesthesiæ, disagreeable sensations of various sorts about the body, feelings of weight in the limbs and joints, loss of sleep, and a continuous feeling of exhaustion. In cases of this class amelioration of symptoms occurs sooner or later, since the psychical condition fluctuates and does not present the steady persistence of the fatigue symptoms of neurasthenia. Neurasthenia is, as Möbius ${ }^{16}$ puts it, a chronic idiopathic exhaustion of the nervous system, usually persistent throughout life. Neurasthenic patients get spurred on by friends and relatives to put forth efforts to "overcome the weakness," with the result that the reaction, in the form of fatigue, becomes more and more marked after such efforts. Many a neurastheniac is driven to the use of stimulants, such as alcohol or morphia. The latter drug is especially resorted to since its consumption is attended with feelings of well-being and heightened capacity for work lasting a few hours. The neurasthenic condition is associated with a deficiency of bodily metabolism, marked by an imperfect excretion of toxic waste-products and a defective capacity for recuperation of the nerve-cells even during rest and sleep. This condition presents points of analogy with myxœdema. Another group of cases of neurasthenia may be caused by sudden psychical disturbance produced by physical shock and traumatism. A sub-class of this group is composed of neurasthenias resulting from sudden fear, not necessarily accompanied by physical shock, and some of these are of grave prognosis. A large and important group of neurasthenias is the congenital form, and allied to this is a hypocondriacal variety, with predominant symptoms of anxiety, doubt, and scruple. These symptoms are closely related to the so-called "phobias" of mental disorder, such as agoraphobia, claustrophobia, and pathophobia. From time to time these symptoms of anxiety, doubt, and scruple acquire great intensity and invade the psychical sphere, giving rise to considerable mental perturbation, emotional disturbance, and even to delusions and impulsive insane acts. Kraepelin thinks that the term neurasthenia should be limited, so as to exclude psychopathic types which are marked by hypochondriacal symptoms, and by "phobias" generally, and believes that in this way a more discriminating diagnosis and a more individualistic treatment will be possible.

10 Jour, of Ment. Science, Oct, 1902 (Presidential Address at the Medico-Psychological Association, by Dr. Wigleswortb. 11 Alcohol and Public Health. 12 Jour. of Ment. Science, Oct.. 1902. 15 Quart. Jour. of Inebriety, Jan., 1901. 14 Loc. cit. 15 Münchener Medicinische Wochenschrift. No. 40, 1902. 16 Studien iiber-Neurasthenie, 1900 .

\title{
SURGERY OF THE BRAIN AND SPINAL CORD.
}

\section{(Concluded from page 99 .)}

Spinal-cord Tumours. - Collins ${ }^{6}$ contributes a long and valuable article on this subject. A previous one by the same author deals with brain tumours. $^{7} \mathrm{He}$ says spinal-cord tumours are more susceptible to surgical treatment than brain tumours and a greater percentage recover, but, nevertheless, the majority of spinal-cord tumours prove fatal through inability to diagnose and localise them on account of their nature and extent and because of the jeopardy to life that operation brings. Spinalcord tumour is rare in comparison with brain tumour and its diagnosis much more difficult. The general symptoms may be: sensory, comprising pain and various disturbances of normal sensation; motor, comprising spasticity, twitchings, painful cramp and paralysis, and increase of myotatic irritability; 
visceral, referable chiefly to the bladder and rectum; trophic, consisting of muscular atrophy, and bed-sores ; and topical, comprising tenderness over the spine and sometimes deformity. The two most difficult things in the diagnosis are to determine whether the tumour is intra- or extradural, and at what segment of the cord it is situated. In intramedullary tumours paraplegia is usually not so complete as with tumour of the meninges, but the great point in the diagnosis between the two is the pain which in intramedullary tumour is rarely an initial symptom but is almost invariably so in tumour of the meninges, and is of great severity. Another symptom in favour of extramedullary situation is the limitation of the motor phenomena, the beginning on one side or in one extremity, or the preponderence of paresis on one side. In order to determine in what segment of the cord the tumour is located it is necessary to make out carefully the limits of anæsthesia and the muscles paralysed. In connection with the former, it must be remembered that the tumour is very often situated higher than the anæsthesia would indicate, and the consensus of opinion would place this 2 to 4 inches above the highest level of the anæesthesia, and more often the latter figure than the former. Spinal sensitiveness is an important aid in localisation, especially if it coincides with the sensory and motor phenomena. The most common and important spinal cord tumours are those of the meninges. Those growing within are nearly twice as common as those growing without the dura, the latter may exist for some time without giving rise to symptoms ; the former cause symptoms early. The favourite site is the dorsal region, the lower and upper end. The histories of three cases are given at length. An important symptom in the first case was abdominal pain, which was diagnosed as appendicitis, and the author refers to other cases in which a similar diagnosis was made. In one the appendix was removed. In others gall-stones or indigestion was diagnosed. The author concludes his valuable paper with an abstract of 70 cases. Thirty of these were operated on, of which 12 were successful, eight partially so, and. 10 wholly unsuccessful-that is to say, they died within a few weeks of the operation. Finally summing up, he says that 50 per cent. of intraspinal tumours are operable, and of these onethird to one-half are benefited by operation. When the surgeon can certainly exclude sepsis the results will be better. The earlier the case can be diagnosed the better is the result likely to be, and once tumour is diagnosed no time must be lost in giving drugs.

6 Med. Rec., Dec. 6, 1902. 7 Med. Rec, Feb. 15, 1902.

\section{Progress in PhOtOTHERAPY.}

Now that the light treatment for dermatoses is becoming more generally trusted and recognised, there have been further attempts at reducing the cumbrous and expensive apparatus first introduced by Finsen. One of these newer forms has been devised by Reyn, a colleague of Finsen's, and termed the "Finsen-Reyn" lamp. By this, only one patient at a time can be treated, which in itself is not a disadvantage, allowing as it does for privacy. The lamp consists of an arc lamp, a concentrating telescope, and a compressor. A current of 20 ampères at 55 volts is required, and the carbons, which are inclined at an angle, are fed automatically. The condenser is only 10 inches long. By specially devised water-cooling arrangements the arc can be brought close to the rock-crystal lenses. In this there are several chambers, two of which contain stationary water (distilled), and two are supplied with running water. Graham, ${ }^{1}$ who supplies the description, states that rather more than 15 minutes are required for a sitting, and that the advantages are-lessened cost per patient, apparently greater rapidity in obtaining satisfactory results, that each patient can be treated privately, its mobility, and the greater ease with which the more inaccessible parts of the body are reached.

A lamp burning carbon or iron electrodes is described by Stopford Taylor. ${ }^{2}$ It is a small apparatus with a water jacket, and its special features consist in its shape, which allows of its being brought with ease against places difficult of access with other lamps, and the fact that the lamp is fixed to a bracket which is one with a specially-made chair, so that pressure can be made and maintained in any position and direction.

Piffard ${ }^{3}$ speaks highly of a lamp constructed after the pattern of Görl with iron, electrodes and three spark gaps excited by means of a static machine with Leyden jars as condensers. In this way, using one eighth inch spark gaps, a light very rich in ultraviolet rays is produced, and a number of separate lamps arranged in series can be actuated by the same current.

O'Brien ${ }^{4}$ states that most of the objections urged against the French lamp can be obviated by prolonging the duration of each sitting and increasing the intensity. With it he has found the reactions in all cases better, and penetration to the deeper tissues more manifest.

The usefulness of the light treatment has not yet reached its limit, for Max Heine ${ }^{5}$ reports a case of chronic pemphigus of two years' duration, and which had not responded to apparently every known remedy, but which was readily and completely cured by light. The treatment here consisted in the light from an arc lamp of 15 amperres being directed upon the patient's skin. An extraordinary improvement was noticed even after the first sitting. Bullæ began to dry up, and no new lesions formed, and the patient was well after nine sittings in 13 days. Blue light was directed upon two bullæ which had been scratched, and healed them. The author asks whether the fatal foliaceous pemphigus might not yield to some such treatment.

Kime ${ }^{6}$ also states confidently that laryngeal tuberculosis may be successfully treated by light ; and that after a few applications pain disappears and aphonia diminishes. He has used the external application of light as an adjuvant in the open-air treatment of phthisis, and regards this as supplying the thing needful in patients for whom the latter would have little chance by itself. In his experience, out of 60 cases of pulmonary tuberculosis treated in this way, the disease was arrested in 12 , improvement marked in 11 , no improvement in 1,5 being dismissed as incurable, while the remaining 31 are yet under 